\title{
A Role for Heme Oxygenase-1 in the Antioxidant and Antiapoptotic Effects of Erythropoietin: The Start of a Good News/Bad News Story?
}

\author{
Lorenzo A. Calò $^{a}$ Paul A. Davis ${ }^{c}$ Antonio Piccoli ${ }^{b}$ Achille C. Pessina $^{a}$ \\ Departments of a Clinical and Experimental Medicine, Clinica Medica 4, and ${ }^{\mathrm{b}}$ Medical and Surgical Sciences, \\ Nephrology, University of Padova, Padova, Italy; ${ }^{\mathrm{C}}$ Department of Nutrition, University of California, \\ Davis, Calif., USA
}

\section{Key Words}

Erythropoietin · Heme oxygenase-1 1 Chronic renal

failure $\cdot$ Dialysis $\cdot$ Cancer anemia

\begin{abstract}
Erythropoietin (EPO) is the major regulator of erythropoiesis. EPO's actions have been shown to be antiapoptotic and dependent on JAK2 signaling and Akt phosphorylation. These effects serve as link between EPO and heme oxygenase-1 (HO-1). HO-1 is an inducible enzyme with potent antioxidant and antiapoptotic activities which are regulated by Akt signaling. EPO's ability to alter cellular systems that involve apoptosis and oxidants suggests that EPO treatments are likely to have multiple and different effects which may start a good news/bad news story. Recombinant human EPO is the recognized treatment of choice to address anemia and to stimulate erythropoiesis in chronic renal failure patients, through its antiapoptotic action which likely involves HO-1. On the other hand, EPO treatment to address anemia in cancer patients, while providing significant improvements in cancer patients' quality of life, its effects on survival are equivocal, likely due to its linkage with HO-1. Two clinical trials of EPO in patients with solid tumors have, in fact, shown specific negative effects on survival. How-
\end{abstract}

ever, EPO's effect on tumor growth and survival is not uniformily pro growth and pro survival, as EPO may act synergistically with chemotherapy to induce apoptosis. Finally, compounds have been synthesized that do not trigger EPO receptor and thus may allow experimental distinction and, therefore, at least potentially affect at the clinical level the tissue-protective effects of EPO (e.g., antiapoptosis) without provoking its other potentially detrimental effects.

Copyright $\odot 2006$ S. Karger AG, Basel

\section{The Good News}

The elucidation of the erythropoietin (EPO) mediated control of erythropoiesis remains an ongoing process, but continues to yield findings of considerable scientific and clinical importance.

EPO has been shown to be a major regulator of proliferation and differentiation of erythroid progenitor cells which acts through its inhibition of proapoptotic caspase activation and attenuation of cell death in response to oxidative stress [1,2]. Mechanistic details of EPO's antiapoptotic action have been recently clarified with the demonstration that the effects of EPO are dependent on JAK2 signaling. The cytoplasmic portion of the EPO re-

\section{KARGER \\ Fax +4161306 1234 E-Mail karger@karger.ch} www.karger.com
(C) 2006 S. Karger AG, Basel 1660-2137/06/1033-0107\$23.50/0

Accessible online at:

www.karger.com/nep
Lorenzo A. Calò, MD, PhD

Department of Clinical and Experimental Medicine, Clinica Medica 4

University of Padova, Via Giustiniani 2

IT-35128 Padova (Italy)

Tel. +39 049821 8701, Fax +39 049875 4179, E-Mail renzcalo@unipd.it 
ceptor, in fact, contains a Box 1 motif that upon EPO binding phosphorylates and thereby activates JAK2 [3]. In addition to the antiapoptotic activity via JAK2, EPO affects phosphatidylinositol 3-kinase (PI3K) and Akt (protein kinase B) activity [3-5]. Akt1, Akt2, and Akt3, the three mammalian isoforms, belong to the cAMP-dependent kinase/protein kinase $\mathrm{G} /$ protein kinase $\mathrm{C}$ superfamily of protein kinases which, once triggered, activates multiple targets with antiapoptotic effects [5]. Interestingly PI3K/Akt-pathway-related responses to oxidative stress and apoptosis have been described at the level of transcriptional regulation of heme oxygenase-1 (HO-1) [6]. HO-1 catalyzes the rate-limiting step in heme degradation, producing carbon monoxide, free $\mathrm{Fe}^{2+}$, and biliverdin. Biliverdin is subsequently reduced to bilirubin by biliverdin reductase. HO-1 is a phase II enzyme induced by oxidative stress [7] and has been shown to possess potent antioxidant and antiapoptotic activities [8]. Both biliverdin and bilirubin display powerful antioxidant properties in vitro, and RNA interference against biliverdin reductase depletes bilirubin and markedly elevates tissue reactive oxygen species levels and causes apoptotic cell death [9]. HO-1 is the inducible isoform of the three $\mathrm{HO}$ isoforms described. HO-1 is increased in response to injurious stimuli such as hyperoxia, hypoxia, as well as exposure to endotoxin and heavy metals, and it has become increasingly evident that $\mathrm{HO}-1$ is a component in an interlocking series of oxidant defenses and signaling systems [7].

Very recently, Salinas et al. [10] have shown that HO-1 is also phosphorylated by Akt which induces an increase in HO-1 activity [10], and PI3K/Akt-pathwayrelated responses to oxidative stress and apoptosis have been described at the level of transcriptional regulation of HO-1 [6].

That Akt is so clearly involved in EPO's activity provides evidence linking EPO and HO-1. Studies on endothelial progenitor cells (EPC) have shown that these cells were mobilized by statins which signal via the PI3K/Akt pathway $[11,12]$, and, in addition, simvastatin's anti-inflammatory and antiapoptotic effects have been shown to occur through PI3K/Akt induction via HO-1 effects [13]. The increases in antioxidant defenses joined with increased expression of HO-1 upon EPO treatment we noted in hemodialysis patients, together with the high degree of a correlation between hemoglobin and HO-1 expression, suggest a direct non-erythropoiesis-related effect of EPO [14] and assume an increased importance in understanding the basis of EPO's effects. These effects result in important clinical significance, as it is well recognized that patients with renal failure, whether on renal replacement therapy or not, are subject to increased oxidative stress which underlies their elevated risk of cardiovascular disease, a major complication in these patients [15]. Also noteworthy are the facts that hemodialysis patients who fail to respond to EPO have an improved response to EPO, resulting in improving anemia when treated with carnitine [16], and that very recently carnitine has been shown to increase the number of colony-forming uniterythroid colonies in mouse bone marrow cell cultures, suggesting that carnitine stimulates erythropoiesis and thereby improves renal anemia [17]. These reports again are consistent with a linkage between EPO, HO-1, and oxidative stress [18], as carnitine has been reported to reduce apoptosis in experimental heart failure [19], and our group [20] reported that carnitine-treated human endothelial cells in culture show increased HO-1 mRNA and protein expression. Moreover, interaction of PI3K/ Akt pathway and apoptosis in heart failure has been traced to transcriptional regulation of HO-1, and oxidative-stress-induced apoptosis is known to play an important role in the pathogenesis of heart failure [21]. Other studies examining HO-1 documented its antiapoptotic role in hemopoietic precursor cells in bone marrow [22, $23]$ and in protection against acute renal failure by EPO through upregulation of HO-1 [24]. Finally, further support for a linkage between EPO and HO-1 comes from other nonerythropoietic effects of EPO, such as those on EPC. EPO is, in fact, a potent regulator of EPC, making EPO a key molecule in the process of vascular repair [25]. Interestingly, also statins have been shown to increase number and differentiation of EPCs via PI3K/Akt pathway, and, as noted earlier, statin-induced antiapoptotic and anti-inflammatory-effect-related responses have been shown to occur via PI3K/Akt-mediated induction of HO-1 [6, 13]. All this is noteworthy insofar, as the clinical outcome in patients with myocardial infarction is strongly correlated with the number of mobilized EPCs from the bone marrow, and the number of EPCs significantly correlates with endothelial function and cardiovascular risk factors in patients having no myocardial infarction $[26,27]$.

Thus there is robust support from a variety of studies, including those from our laboratory, for HO-1's interrelated roles as both an antioxidant as well as a mediator of the antiapoptotic action of EPO, particularly with respect to EPO's effect on hemopoietic cells in hemodialysis patients. 


\section{The Bad News}

The ability of EPO to alter cellular systems that involve apoptosis and oxidants suggests that EPO's overall effects may not all be assumed to be either selective or benign. This is particularly so given the Jekyll-and-Hydelike nature of oxidants, wherein they can function to damage biomolecules and tissues as well as to mediate aberrant signals, but are nonetheless critical components involved in normal cell and organ system function and signal transduction. The changes accompanying chronic systemic EPO elevation and their connection to the pathology found remain to be fully explored. However, the growing data regarding EPO's effects on HO-1 coupled to the studies showing its antiapoptotic effects suggest that more attention may need to be paid to the potential for EPO to reduce or prevent apoptosis, when it is a desired outcome [28]. In fact, a direct growth regulation by EPO in prostate cancer has been shown [29], and evidence that increased autocrine EPO signaling promotes survival in breast cancer cells has also been provided [30]. Arcasoy et al. [29] have, in fact, shown growth regulation by EPO and its receptor in an autocrine or paracrine manner in prostate cancer. Similarly, Acs et al. [30] have provided evidence that increased autocrine EPO signaling induced by moderate levels of hypoxia in breast cancer cells upregulates bcl-2 and bcl-XL, inhibits hypoxia-induced apoptosis, and promotes survival [30].

It is well recognized that EPO treatment provides significant improvements in terms of quality of life in cancer patients with anemia. However, a recent report by the European Organization for Research and Treatment of Cancer (EORTC) [31] indicated that while EPO can be shown to provide significant quality of life improvements in cancer patients with anemia, its effects on survival were equivocal. The EORTC report also examined in depth the results of two specific clinical trials, where EPO's effect on patient survival provoked specific concerns [32, 33]. The first such trial [32] was a randomized, prospective trial using recombinant EPO and involved patients with metastatic breast cancer. The trial was terminated early due to impaired patient survival that was associated with disease progression in those patients receiving recombinant $\mathrm{EPO}$ when compared to patient survival and disease progression of the placebo arm. In the second trial [33], in patients with cancer of head and neck, it was found that EPO treatment was associated with a poorer progression-free survival in those patients randomized into the recombinant human EPO arm.
As is the case for EPO, the connection of EPO and HO-1 is also supported by HO-1 involvement in cancer cell proliferation. HO-1 is, in fact, upregulated in many tumors and plays a critical role in tumor growth [34]. In our laboratory further evidence was found for the involvement of HO-1 in tumor cell growth. We have found, in fact, that doxazosin, an alpha blocker used to treat benign prostatic hyperplasia, decreases HO-1 mRNA and protein levels in human prostate biopsy specimens, providing a mechanism for the proapoptotic actions of doxazosin [35] and further suggesting that HO-1 activity and prostate cell apoptosis are linked [36].

Other potential side effects of EPO continue to be examined, with thrombosis and vascular events being a particular focus [37]. Bohlius et al. [38] have recently reported the results of a systematic meta-analysis of EPO based on twelve trials published up to 2001. Overall, the authors concluded that there was no conclusive evidence of an increased risk of hypertension and thromboembolic events or related complications in cancer patients treated with EPO. However, several reports have described a high rate of thrombotic and vascular events in EPO-treated groups [39]. One potential mechanism for this association is that EPO has been reported to show procoagulant properties that predispose to thrombosis [40, 41].

Given the extensive use of EPO in clinical practice, further investigations specifically addressing the relationship(s) between EPO and HO-1 and their effects on cancer growth/survival are warranted. Of note, in response to the issue of EPO's effect on cancer patient survival, the EORTC report [31] suggested that 'the issues of tumor response/progression and survival must be carefully studied in order to provide clear guidelines for the future'. In a recent study, Pajonk et al. [28] have gone a step further and suggested that the EPO use should be restricted in patients suffering from EPO-receptor-expressing cancers.

On the other hand, there is recent experimental evidence that EPO may act synergistically with chemotherapeutic agents [42] and increase tumor cell apoptosis [43] and that HO-1, in addition to be antiapoptotic in some cells, has been found to act as proapoptotic in others [44] and that these effects also link EPO with HO-1, making the entire argument EPO-HO-1/cancer growth and survival being very much in need of further clarification. 


\section{Conclusions}

EPO actions appear to be linked to oxidative stress mediators and to HO- 1 resulting from EPO's widespread antiapoptotic effects which strongly point to a central role for HO-1 as a mediator of EPO and confirm its status as a major antioxidant/antiapoptotic factor. The recognition of such a central role of HO-1 is likely to be useful in several different conditions. This includes the development of therapeutic strategies aimed at increasing the HO- 1 activity and thereby counteracting oxidative stress and apoptosis, specifically in chronic renal failure patients with their increased cardiovascular disease risk. The connection between EPO, HO-1, oxidative stress, and diseases such as cancer and heart disease suggests that the use of EPO to address anemia needs to be carefully assessed, as the perceived benefits may be accompanied, in some conditions such as cancer, by significant negative effects. Our limited understanding of the interaction of EPO and HO-1 and the oxidant and other pathways they modify as well as the apparently contradictory effects for both HO-1 and EPO suggest that EPO effects and its clinical usage are very much in need of further clarification. The future of EPO- and HO-1-related research and clinical modalities is even more exciting, as Leist et al. [45] have published results with compounds that trigger EPOmediated tissue-protective pathways without cross talk with the hematopoietic system, suggesting that it will be possible to evoke, in specific target cell and organs, EPO's protective effects (e.g., antiapoptosis), avoiding its other potentially detrimental effects.

\section{References}

- Sharples EJ, Patel N, Brown P, Stewart K, Mota-Philipe H, Sheaff M, Kieswich J, Allen D, Harwood S, Raftery M, Thiemermann C, Yaqoob MM: Erythropoietin protects the kidney against the injury and dysfunction caused by ischemia-reperfusion. J Am Soc Nephrol 2004; 15:2115-2124.

$\checkmark 2$ Testa U: Apoptotic mechanisms in the control of erythropoiesis. Leukemia 2004;18:11761199.

>3 Cheung JY, Miller BA: Molecular mechanisms of erythropoietin signaling. Nephron 2001;87: 215-222.

4 Bahlmann FH, Song R, Boehm SM, Mengel M, von Wasielewski R, Lindschau C, Kirsch T, de Groot K, Laudeley R, Niemczyk E, Guler F, Menne J, Haller H, Fliser D: Low-dose therapy with the long-acting erythropoietin analogue darbepoetin alpha persistently activates endothelial Akt and attenuates progressive organ failure. Circulation 2004;110:1006-1012.

$\checkmark 5$ Chong ZZ, Kang JQ, Maiese K: Erythropoietin is a novel vascular protectant through activation of Akt 1 and mitochondrial modulation of cysteine proteases. Circulation 2002;106: 2973-2979.

-6 Martin D, Rojo AI, Salinas M, Diaz R, Gallardo G, Alam J, De Galarreta CM, Cuadrado A: Regulation of heme oxygenase-1 expression through the phosphatidylinositol 3-kinase/Akt pathway and the Nrf2 transcription factor in response to the antioxidant phytochemical carnosol. J Biol Chem 2004;279:8919-8929.

7 Maines MD: The heme oxygenase system: a regulator of second messenger gases. Annu Rev Pharmacol Toxicol 1997;37:517-554.

$>8$ Durante W: Heme oxygenase-1 in growth control and its clinical application to vascular disease. J Cell Physiol 2003;195:373-382. $\checkmark 9$ Miralem T, Hu Z, Torno MD, Lelli KM, Maines MD: Small interference RNA-mediated gene silencing of human biliverdin reductase, but not that of heme oxygenase-1, attenuates arsenite-mediated induction of the oxygenase and increases apoptosis in 293A kidney cells. J Biol Chem 2005;280:1708417092.

10 Salinas M, Wang J, Rosa de Sagarra M, Martin D, Rojo AI, Martin-Perez J, Ortiz de Montellano PR, Cuadrado A: Protein kinase Akt/PKB phosphorylates heme oxygenase- 1 in vitro and in vivo. FEBS Lett 2004;578:90-94.

11 Dernbach E, Urbich C, Brandes RP, Hofmann WK, Zeiher AM, Dimmeler S: Antioxidative stress-associated genes in circulating progenitor cells: evidence for enhanced resistance against oxidative stress. Blood 2004; 104: 3591-3597.

12 Dimmeler S, Aicher A, Vasa M, Mildner-Rihm C, Adler K, Tiemann M, Rutten H, Fichtlscherer S, Martin H, Zeiher AM: HMG-CoA reductase inhibitors (statins) increase endothelial progenitor cells via the PI 3-kinase/Akt pathway. J Clin Invest 2001;108:391-397.

$>13$ Lee TS, Chang CC, Zhu Y, Shyy JY: Simvastatin induces heme oxygenase-1: a novel mechanism of vessel protection. Circulation 2004; 110:1296-1302.

14 Calò LA, Stanic L, Davis PA, Pagnin E, Munaretto G, Fusaro M, Landini S, Semplicini A, Piccoli A: Effect of epoetin on HO-1 mRNA level and plasma antioxidants in hemodialysis patients. Int J Clin Pharmacol Ther 2003;41: 187-192.

15 Locatelli F, Canaud B, Eckardt KU, Stenvinkel $\mathrm{P}$, Wanner C, Zoccali C: Oxidative stress in end-stage renal disease: an emerging threat to patient outcome. Nephrol Dial Transplant 2003;18:1272-1280.
16 Hurot JM, Cucherat M, Haugh M, Fouqué D: Effects of $L$-carnitine supplementation in maintenance hemodialysis patients: a systematic review. J Am Soc Nephrol 2002;13:708714.

17 Kitamura Y, Satoh K, Satoh T, Takita M, Matsuura A: Effect of $L$-carnitine on erythroid colony formation in mouse bone marrow cells. Nephrol Dial Transplant 2005;20:981-984.

18 Calò LA, Davis PA, Semplicini A, Pessina AC: $L$-Carnitine and erythropoiesis: relationship with haeme oxygenase-1. Nephrol Dial Transplant 2005;20:1769-1770.

19 Vescovo G, Ravara B, Gobbo V, Sandri M, Angelini A, Della Barbera M, Dona M, Peluso G, Calvani M, Mosconi L, Dalla Libera L: LCarnitine: A potential treatment for blocking apoptosis and preventing skeletal muscle myopathy in heart failure. Am J Physiol Cell Physiol 2002;283:C802-C810.

20 Calò LA, Pagnin E, Davis PA, Semplicini A, Nicolai R, Calvani M, Pessina AC: Antioxidant effect of $L$-carnitine and its short chain esters: relevance for the protection from oxidative stress related cardiovascular damage. Int $\mathbf{J}$ Cardiol 2006;107:54-60.

-21 Sawyer DB, Siwik DA, Xiao L, Pimentel DR, Singh K, Colucci WS: Role of oxidative stress in myocardial hypertrophy and failure. $\mathrm{J}$ Mol Cell Cardiol 2002;34:379-388.

22 Ferris CD, Jaffrey SR, Sawa A, Takahashi M, Brady SD, Barrow RK, Tysoe SA, Wolosker H, Baranano DE, Dore S, Poss KD, Snyder SH: Haem oxygenase-1 prevents cell death by regulating cellular iron. Nat Cell Biol 1999;1:152157.

23 Lutton JD, Levere RD, Abraham NG: Physiologic role of heme and cytochrome P-450 in hematopoietic cells. Proc Soc Exp Biol Med 1991;196:260-269. 
24 De Beuf A, Ferhulst A, Dams G, Dawe S, De Broe MF: Erythropoietin protects the kidney against acute renal failure by upregulation of heme oxygenase-1 (abstract). J Am Soc Nephrol 2004; 15:638.

-25 Bahlmann FH, de Groot K, Duckert T, Niemczyk E, Bahlmann E, Boehm SM, Haller H, Fliser D: Endothelial progenitor cell proliferation and differentiation is regulated by erythropoietin. Kidney Int 2003;64:1648-1652.

-26 Vasa M, Fichtlscherer S, Adler K, Aicher A, Martin H, Zeiher AM, Dimmeler S: Increase in circulating endothelial progenitor cells by statin therapy in patients with stable coronary artery disease. Circulation 2001;103:28852890.

-27 Vasa M, Fichtlscherer S, Aicher A, Adler K, Urbich C, Martin H, Zeiher AM, Dimmeler S: Number and migratory activity of circulating endothelial progenitor cells inversely correlate with risk factors for coronary artery disease. Circ Res 2001;89:E1-E7.

-28 Pajonk F, Weil A, Sommer A, Suwinski R, Henke M: The erythropoietin-receptor pathway modulates survival of cancer cells. Oncogene 2004;23:8987-8991.

-29 Arcasoy MO, Amin K, Vollmer RT, Jiang X, Demark-Wahnefried W, Haroon ZA: Erythropoietin and erythropoietin receptor expression in human prostate cancer. Mod Pathol 2005; 18:421-430.

-30 Acs G, Chen M, Xu X, Acs P, Verma A, Koch $\mathrm{CJ}$ : Autocrine erythropoietin signaling inhibits hypoxia-induced apoptosis in human breast carcinoma cells. Cancer Lett 2004;214:243251.

-31 Bokemeyer C, Aapro MS, Courdi A, Foubert J, Link H, Osterborg A, Repetto L, Soubeyran P: EORTC guidelines for the use of erythropoietic proteins in anaemic patients with cancer. Eur J Cancer 2004;40:2201-2216.
32 Leyland-Jones B: Breast cancer trial with erythropoietin terminated unexpectedly. Lancet Oncol 2003;4:459-460.

33 Henke M, Laszig R, Rube C, Schäfer U, Haase KD, Schilcher B, Mose S, Beer KT, Burger U, Dougherty C, Frommhold H: Erythropoietin to treat head and neck cancer patients with anaemia undergoing radiotherapy: randomised, double-blind, placebo-controlled trial Lancet 2003;362:1255-1260.

34 Fang J, Akaike T, Maeda H: Antiapoptotic role of heme oxygenase $(\mathrm{HO})$ and the potential of $\mathrm{HO}$ as a target in anticancer treatment. Apoptosis 2004;9:27-35.

-35 Calò LA, Pagnin E, Davis PA, Loddo M, Mian C, Semplicini A, Pycha A: Effect of doxazosin on oxidative stress related proteins in benign prostatic hyperplasia. Urol Int 2006;76:3641.

36 Kyprianou N: Doxazosin and terazosin suppress prostate growth by inducing apoptosis: clinical significance. J Urol 2003;169:15201525.

37 Stasi R, Amadori S, Littlewood TJ, Terzoli E, Newland AC, Provan D: Management of cancer-related anemia with erythropoietic agents: doubts, certainties, and concerns. Oncologist 2005; 10:539-554.

38 Bohlius J, Langensiepen S, Schwarzer G, Seidenfeld J, Piper M, Bennet C, Engert A: Erythropoietin for patients with malignant disease. Cochrane Database Syst Rev 2004: CD003407.
39 Wun T, Law L, Harvey D, Sieracki B, Scudder SA, Ryu JK: Increased incidence of symptomatic venous thrombosis in patients with cervical carcinoma treated with concurrent chemotherapy, radiation, and erythropoietin. Cancer 2003;98:1514-1520.

40 Wolf RF, Peng J, Friese P, Gilmore LS, Burstein SA, Dale GL: Erythropoietin administration increases production and reactivity of platelets in dogs. Thromb Haemost 1997; 78: 1505-1509.

41 Stohlawetz PJ, Dzirlo L, Hergovich N, Lackner E, Mensik C, Eichler HG, Kabma E, Geissler K, Jilma B: Effects of erythropoietin on platelet reactivity and thrombopoiesis in humans. Blood 2000;95:2983-2989.

42 Blackwell K, Gascon P, Sigounas G, Jolliffe L: rHuEPO and improved treatment outcomes: potential modes of action. Oncologist 2004; 9(suppl 5):41-47.

43 Carvalho G, Lefaucheur C, Cherbonnier C, Metivier D, Chapel A, Pallardy M, Bourgeade MF, Charpentier B, Hirsch F, Kroemer G: Chemosensitization by erythropoietin through inhibition of the NF-kappaB rescue pathway. Oncogene 2005;24:737-745.

44 Liu XM, Chapman GB, Wang H, Durante W: Adenovirus-mediated heme oxygenase-1 gene expression stimulates apoptosis in vascular smooth muscle cells. Circulation 2002;105: 79-84.

45 Leist M, Ghezzi P, Grasso G, Bianchi R, Villa P, Fratelli M, Savino C, Bianchi M, Nielsen J, Gerwien J, Kallunki P, Larsen AK, Helboe L, Christensen S, Pedersen LO, Nielsen M, Torup L, Sager T, Sfacteria A, Erbayraktar S, Erbayraktar Z, Gokmen N, Yilmaz O, CeramiHand C, Xie QW, Coleman T, Cerami A, Brines M: Derivatives of erythropoietin that are tissue protective but not erythropoietic. Science 2004;305:239-242. 